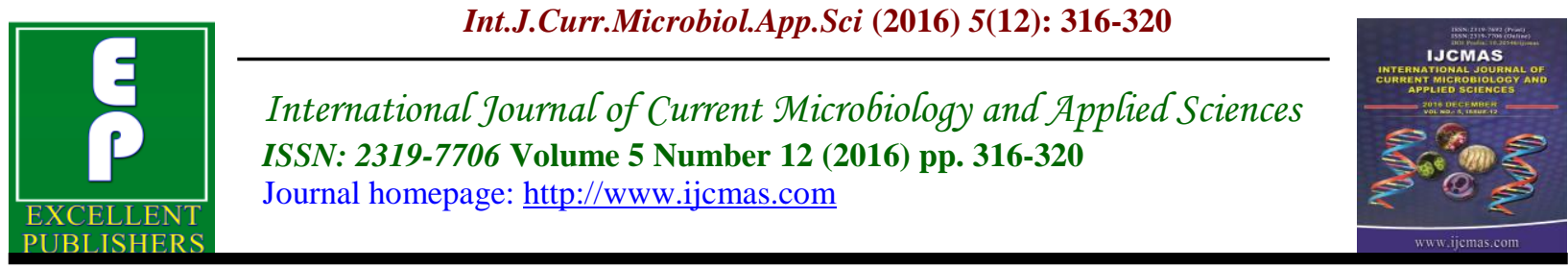

Original Research Article

http://dx.doi.org/10.20546/ijcmas.2016.512.034

\title{
First Report of Penicillium adametzioides from Decayed Grapes (Vitis vinifera) in Pakistan
}

\author{
Ibatsam Khokhar $^{1 *}$ and Rukhsana Bajwa ${ }^{2}$ \\ ${ }^{1}$ Department of Biological Sciences, Forman Christian College \\ (A Chartered University), Pakistan \\ ${ }^{2}$ Institute of Agricultural Sciences, University of the Punjab Lahore, Pakistan \\ *Corresponding author
}

\section{A B S T R A C T}

Keywords

Grapes,

Penicillium

adametzioides,

Rot, Morphology.

Article Info

Accepted:

18 November 2016

Available Online:

10 December 2016
In this study Penicillium adametzioides was found to be the cause of postharvest rot of stored grapes (Vitis vinifera) in Pakistan. Infected fruit tissues were cultured on malt extract agar (MEA) and Czapek $(\mathrm{Cz})$ medium at $25^{\circ} \mathrm{C}$. The pathogen was identified as $P$. adametzioides on the basis of morphological and molecular characteristics. Pathogenicity tests conducted on healthy fruits under laboratory conditions showed typical rot symptoms after seven to fourteen days. This is the first report of post harvest rot of grapes caused by $P$. adametzioides in Pakistan.

\section{Introduction}

Penicillium is the major cause of degradation of fruits during pre harvesting and post harvesting stages, thus Penicillium cause substantial economic losses due to spoilage. In december 2011, during a survey of local fruit market in Lahore (Pakistan), samples of decayed grapes have been collected. To clarify the causal agents of those symptoms, fruit samples were obtained from a local fruit market, kotlakhpat, Lahore and examined at laboratory. From the necrotic areas, a bluegrey fungal growth was observed. Temporary slides of diseased tissues were made and observed under light microscope. Small pieces $(3 \mathrm{~mm})$ of rotting tissue were taken from the fruits and surface sterilized with $1 \% \mathrm{Na}(\mathrm{O}) \mathrm{Cl}$ then placed onto $2 \%$ malt extract agar (MEA) and incubated at $25^{\circ} \mathrm{C}$ in darkness for 5 days. As a result, a species belonging to the genus Penicillium subgenus Aspergilloides was consistently found associated to the described symptoms. A recent record proves that $P$. adametzioides Abe ex G. Smith (subgenus Aspergilloides) was the causal agent of a similar fruit rot in Korea (Jian Xin Deng et al., 2012). According to key (Raper and Thom, 1949; Pitt, 1979, 1985; Ramírez, 1982; Samson et al., 1995; Pitt and Hocking, 1997, 1999) this species is primarily characterized by its relatively slow growth on Czapek-based 
media and MEA at $25^{\circ} \mathrm{C}$, heavy blue-grey sporulation, forming crusts, production of a soluble yellow pigment on the media, and inability to grow at 5 and $37{ }^{\circ} \mathrm{C}$ on both $\mathrm{Cz}$ and MEA. Thus, in order to allow the confirmation of the fungus identity obtained in this study the resulting fungal colonies were subcultured on Czapek-solution agar (Cz), 2\% MEA, CYA and $\mathrm{G} 25 \mathrm{~N}$ at $25{ }^{\circ} \mathrm{C}$. The description of our fungal specimen is as follows:
On MEA, $25{ }^{\circ} \mathrm{C}, 7$ days: Colonies were variable in size from $20-30 \mathrm{~mm}$ in diameter, convolute centrally, outer areas plane or radially sulcate, colony centres umbonate. Mycelium usually white to cream then became greenish grey or greenish glaucous due to conidiogenesis. White marginal zone was present. Reverse of the colony was pale to yellow brown. Exudates and soluble pigment are absent (Plate 1).

Fig.1 Conidiophores and conidia of Penicillium adametzioides. $(\mathrm{bars}=10 \mu \mathrm{m})$.

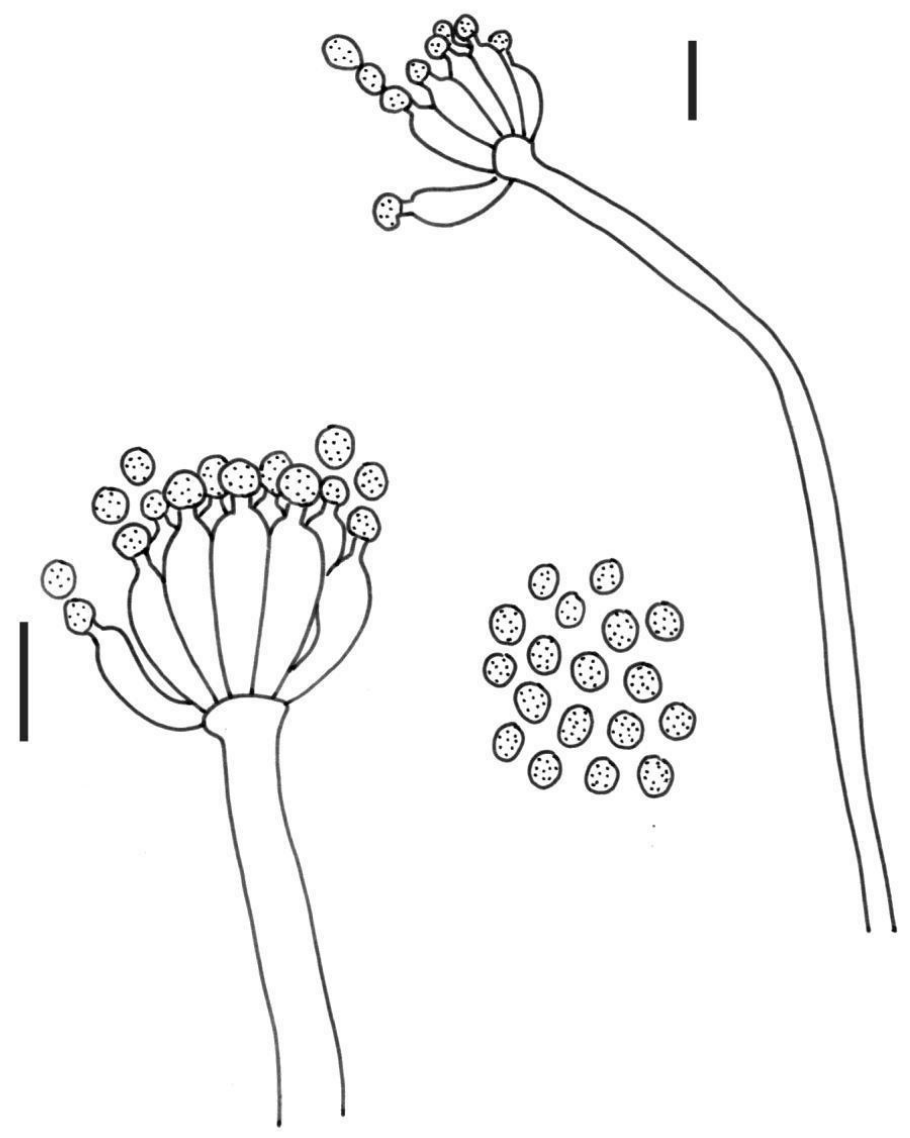


Plate.1 Penicillium adametzioides.A-C \& G, 7-days old Colony at MEA, CZ, CYA and G25N, respectively. D-F \& H, Reverse on MEA, CZ, CYA and G25N, respectively. I,

Microphotographs $(100 \mathrm{X})$. (bar $=10 \mu \mathrm{m})$.
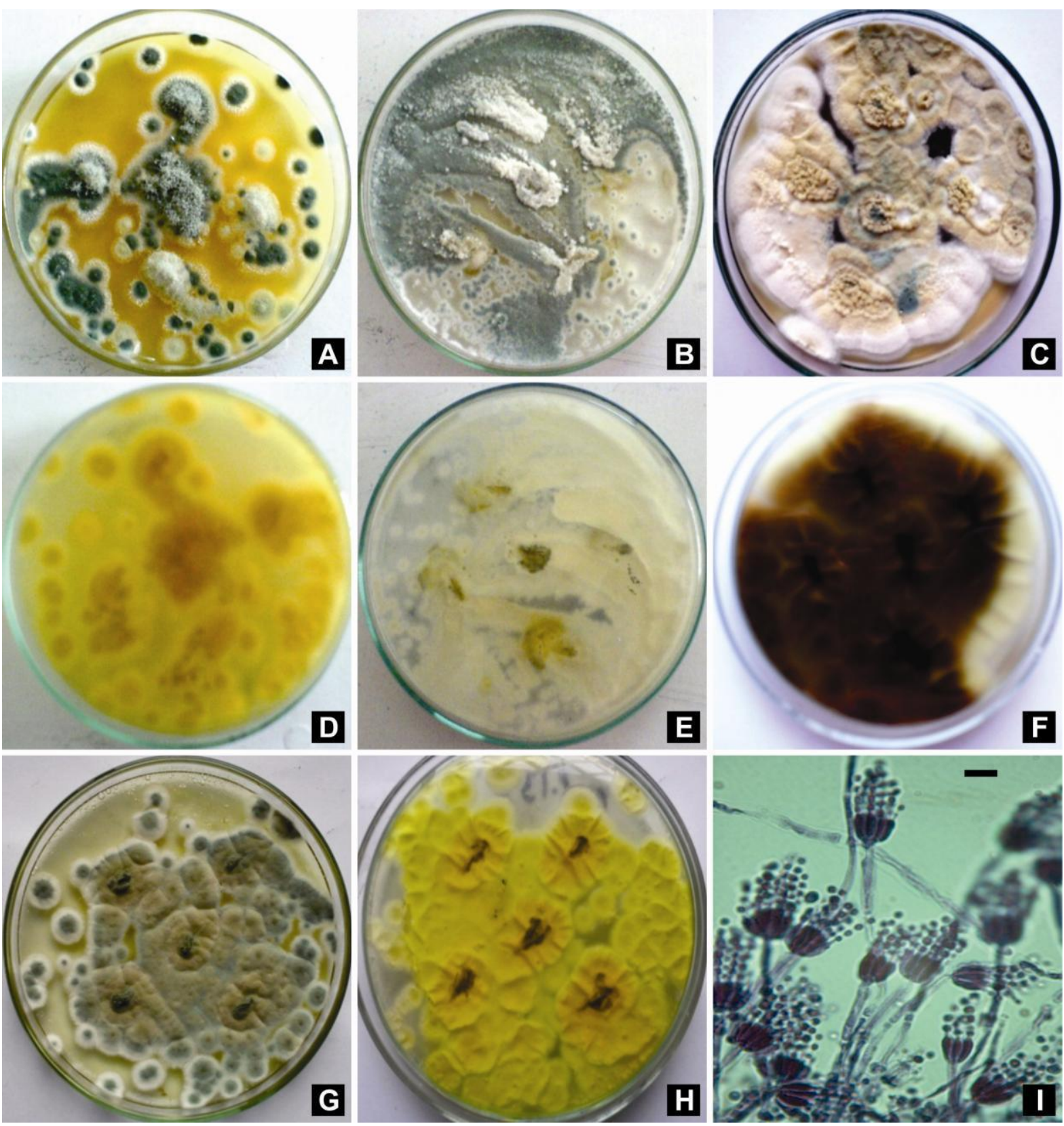

On CZ, $25{ }^{\circ} \mathrm{C}, 7$ days: Colonies were variable in size from $20-30 \mathrm{~mm}$ in diameter, somewhat deep, lightly sulcate, clearly funiclose, margins low and entire. Mycelium usually white to cream then became greenish glaucous due to conidiogenesis. Reverse of the colony was pale to yellow brown. Exudates and soluble pigment are absent.

On G25N, $25{ }^{\circ} \mathrm{C}, 7$ days: Colonies were variable in size from $14-18 \mathrm{~mm}$ in diameter, umbonate, dense and velutinous. Mycelium 
usually white to cream then became grayish green or greenish glaucous due to conidiogenesis. Reverse of the colony was uncolored to yellow. Exudates and soluble pigment are absent.

Conidiophores originated from funicles, less commonly from surface or aerial hyphae. Stipe was smooth walled, short and slender. Its length was more than 40-100 (-150) $\times$ 2.0-3.0 $\mu \mathrm{m}$ wide. Monoverticillate, nonvesiculate (Figure 1) or slightly swollen at the apices 4-6 $\mu \mathrm{m}$.

Phialides in verticils of 5-8, with tappering collula. Phialides were ampulliform, 7-10 (13) $\times 2.2-$

$3.0 \mu \mathrm{m}$. Conidia smooth to finely rough walled, spheroidal to ellipsoidal, 2.2-3.0 $\times$ 1.8-2.5 $\mu \mathrm{m}$.

To confirm the identity of the causal fungus, extraction of total DNA from the mycelia and conidia of the isolates was done by modified 2\% CTAB method (Doyle and Doyle, 1990). The internal transcribed spacer (ITS) region of rDNA was amplified with primers ITS1/ITS4 (White et al., 1990). A GenBank BLAST search with the present data revealed that the ITS sequences showed $91.4 \%$ similarity with that of $P$. adametzioides (DQ117965) and $P$. adametzioides (AF033403). The resulting approximately 600 bp ITS sequences were deposited in GenBank at NCBI (National centre for biotechnology information) under accession numbers HG326277.

\section{Pathogenicity test}

Pathogenicity of the isolated organism was confirmed on healthy grapes. Conidial suspension $\left(2 \times 10^{4}\right.$ conidia $\left.\mathrm{ml}^{-1}\right)$ from a pure culture of the fungus was directly inoculated by means of a sterile needle into the subcutaneous layer of grapes. Infested fruits were incubated at $25^{\circ} \mathrm{C}$ for 7 to 14 days. Typical symptoms were produced on the inoculated fruits after 7 days. The pathogen from the inoculated fruits was re-isolated on $2 \%$ MEA medium as described above. The morphological and molecular characteristics of the re-isolated organism were compared with the original pathogen. The pathogen was identified from all infected fruit samples. In a survey of grapes postharvest losses in commercial markets in Lahore, Pakistan, blue mould symptoms were observed on up to $15-20 \%$ of grapes. A culture of the fungus has also been deposited at First fungal culture bank of Pakistan (FCBP),Institute of Agricultural Sciences, University of the Punjab Lahore, Pakistan, for further studies.

\section{References}

Doyle, J.J. and Doyle, J.L. 1990. Isolation of plant DNA from fresh tissue. Focus, 12: 13-15.

Jian, X.D., Narayan, C.P., Hyun, K.S., Ji, H.L., Yong, S.H. and Seung, H.Y. 2012. First Report on Isolation of Penicillium adametzioides and Purpureocillium lilacinum from Decayed Fruit of Cheongsoo Grapes in Korea, Mycobiol., 40(1) : 66-71.

Pitt, J.I. 1979. The genus Penicillium and its teleomorphic states Eupenicillium and Talaromyces. Academic, London.

Pitt, J.I. 1985. A laboratory guide to common Penicillium species. Commonwealth Scientific and Industrial Research Organization Division of Food Research, North Ryde.

Pitt, J.I., and Hocking, A.D. 1997. Fungi and food spoilage. Academic Press, Chapman and Hall, Sydney.

Pitt, J.I., and Hocking, A.D.1999. Fungi and Food Spoilage, 2nd edn. Aspen 
Publishers, Inc., Gaithersburg, pp 234, 511,512 .

Ramírez, C. 1982. Manual and atlas of the Penicillia. Elsevier Biomedical Press, Amsterdam/New York/Oxford.

Raper, K.B., and Thom, C.H. 1949. A manual of the Penicillia. Williams and Wilkins, Baltimore.

Samson, R.A., Hoekstra, E.S., Frisvad, J.C., and Filtenborg, O. 1995. Introduction to food-borne fungi. Centraalbureau voor Schimmelcultures, Baarn.

White, T.J., Bruns, T., Lee, S. and Taylor, J.W. 1990. Amplification and direct sequencing of fungal ribosomal RNA genes for phylogenetics. In: Innis MA, Gelfand DH, Sninsky JJ, White TJ (eds) PCR protocols: a guide to methods and applications. Academic, San Diego, pp 315-322.

\section{How to cite this article:}

Ibatsam Khokhar and Rukhsana Bajwa. 2016. First Report of Penicillium adametzioides from Decayed Grapes (Vitis vinifera) in Pakistan. Int.J.Curr.Microbiol.App.Sci. 5(12): 316-320. doi: http://dx.doi.org/10.20546/ijcmas.2016.512.034 